\title{
TUBERCULAR MASTITIS: A RARE ENTITY OF DIAGNOSTIC DILEMMA
}

\author{
Reena Kouli ${ }^{1}$, Asha Borah ${ }^{2}$, Daljeet Kaur ${ }^{3}$, Jasmine Teronpi ${ }^{4}$
}

\section{HOW TO CITE THIS ARTICLE:}

Reena Kouli, Asha Borah, Daljeet Kaur, Jasmine Teronpi. "Tubercular Mastitis: A Rare Entity of Diagnostic Dilemma". Journal of Evolution of Medical and Dental Sciences 2015; Vol. 4, Issue 83, October 15;

Page: 14619-14621, DOI: $10.14260 /$ jemds/2015/2077

ABSTRACT: Tubercular mastitis is one of the rarest manifestation of extrapulmonary tuberculosis. Its overall incidence is $3 \%$ of surgically treated breast lesions in developing countries like India. It usually presents as a solitary, ill-defined, unilateral hard lump in the upper outer quadrant of the breast. Due to its rarity, the disease is often overlooked and misdiagnosed. Even it can easily be missed by sophisticated radiological investigations. In India, merely 0.64 and 3.59 percent of tubercular mastitis has been reported amongst all mammary conditions. In this study, we will be highlighting this rare case from north-east India and the inevitable role of FNAC in arriving the challenging diagnosis of tubercular mastitis. The patient presented with mastitis with prior antibiotic treatment without any evidence of pulmonary tuberculosis. Timely and accurate diagnosis of this rare entity is strongly emphasized as the disease is totally curable with antitubercular drugs and surgery is seldom required.

KEYWORDS: Tuberculosis, Extrapulmonary, Breast, FNAC.

INTRODUCTION: Tuberculosis is called the great mimicker because of its potential to involve any organ and mimic other illness. Tubercular mastitis is one of the rarest presentations of extra pulmonary tuberculosis. Females are more frequently affected, especially in their reproductive age.1,2 This could be because of the increased susceptibility to trauma and infection when the breast is undergoing constant remodeling. ${ }^{3}$

The usual presentation is a solitary, ill-defined, unilateral hard lump in the upper outer quadrant. Typically, constitutional symptoms and failing general health are found in $20 \%$ of patient's only. ${ }^{4}$ Non-specific radiological findings are common due to poor immunological reactivity to the bacillus.

CASE REPORT: A 25 year-old married HIV negative female presented with a swelling in the upper outer quadrant of left breast since 3 weeks. It was slightly mobile, measuring approximately $5 \mathrm{~cm} \times 5 \mathrm{~cm}$ in size, firm in consistency, with an overlying normal skin. The swelling was insidious in onset and no preceding history of any trauma or infection in the site was present. Also there was no history of fever, night sweats, weight loss, and cough with sputum production. There was no fluctuation in the size of the swelling after being first recognised by the patient. The patient gave no history of exposure to tuberculosis and no past history of breast or ovarian disease or tuberculosis. Examination of nipple revealed no abnormality. No axillary lymph nodes were palpable bilaterally. Opposite breast was completely normal. General physical examination and systemic examination revealed no abnormality. Her biochemical tests were within normal limits. Complete blood count showed a normal study except for a moderate rise in Erythrocyte sedimentation rate (ESR). Ultrasonography of breast suggested the possibility of mastitis. Due to its inconclusive clinical features and radio diagnosis, fine needle aspiration of the breast lump was advised. 
Fine needle aspiration cytology was performed using a 22 gauze needle. Aspiration done from different areas yielded bloody as well as purulent aspirate. May Grunwald Giemsa stained smears showed a moderately cellular picture comprising of well-formed granulomas (Figure 1) consisting of loose clusters of epithelioid cells, plenty of lymphocytes in a haemorrhagic background suggesting a granulomatous lesion with the possibility of tuberculosis.

Simultaneously, Ziehl-Neelsen stain was done from the purulent aspirate obtained from the inflamed area which revealed acid fast bacilli (Figure 2) in a background full of inflammatory cells, predominantly polymorphs. Hence, the complete diagnosis of tubercular mastitis was made and the patient was put on antitubercular drugs. The lesion healed dramatically within 8 months.

DISCUSSION: Tuberculosis of the breast is exceptionally uncommon even in countries endemic for pulmonary and extrapulmonary tuberculosis. Extrapulmonary tuberculosis in the breast may present as a mass, discharging sinus, cold abscess or non-healing ulcers mimicking carcinoma. ${ }^{5}$ Differentiation from granulomatous mastitis by histoplathological examination is paramount because of the hazardous implications of corticosteroid therapy in an immunosuppressed patient with tuberculosis. Due to paucicellularity of tubercle bacilli in the lesion, mycobacterial culture may often be negative. Due to vaning immunity of the patient, radiological findings may fail to support the diagnosis of tubercular mastitis. In presence of a high clinical suspicion of TB, negative culture and absence of demonstrable acid fast bacillus on Ziehl neelsen stain, a trial of antitubercular therapy is warranted. As tubercular mastitis most commonly presents as a breast lump, it has an ability to masquerade a number of conditions like as fibroadenoma, fibroadenosis, malignancy or breast abscess. It is therefore very important that pathologists should always include tubercular mastitis as a differential in all cases presenting with breast lump specially in a tubercular endemic country like India. Correct diagnosis and timely initiation of treatment with standard antituberculous therapy for 6 months usually results in good clinical response and can save the patient from unnecessary surgery. ${ }^{6}$

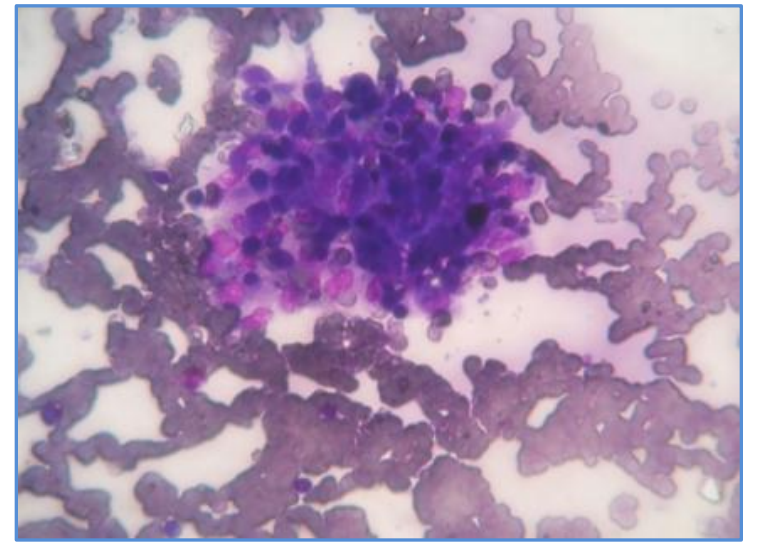

Fig. 1: MGG (100x) smear showing a well formed granuloma

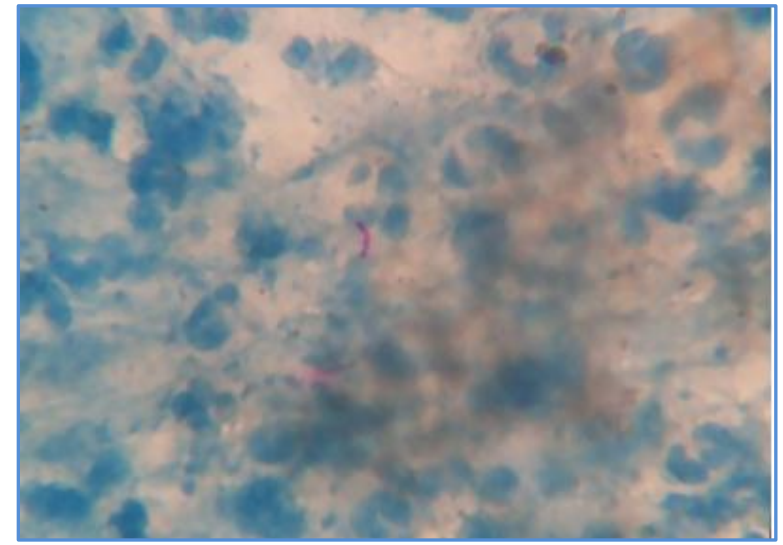

Fig. 2: ZN (100x) smear showing acid fast bacilli 


\section{BIBLIOGRAPHY:}

1. Jalali U, Rasul S, Khan A, Baig N, Khan A, Akhter R. Tuberculous mastitis. J Coll Physicians Surg Pak. 2005; 15:234-7.

2. O'Reilly M, Patel KR, Cummins R. Tuberculosis of the breast presenting as carcinoma. Mil Med. 2000; 165:800-2.

3. Raw N. Tuberculosis of the breast. Br Med J. 1924; J: 657-8.

4. Shinde SR, Chandawarkar RY, Deshmukh SP. Tuberculosis of the breast masquerading as carcinoma: A study of 100 patients. World J Surg 1995; 19:379-81.

5. Field AS. Infectious diseases. In: Orell SR, Sterrett GF, editors. Fine Needle Aspiration Cytology. 5th ed. Gurgaon: Elsevier Limited; 2012. p. 459-61.

6. Tewari M, Shukla HS. Breast tuberculosis: Diagnosis, clinical features and management. Indian J Med Res. 2005; 122:103-10.

\section{AUTHORS:}

1. Reena Kouli

2. Asha Borah

3. Daljeet Kaur

4. Jasmine Teronpi

\section{PARTICULARS OF CONTRIBUTORS:}

1. Associate Professor, Department of Pathology, Assam Medical College and Hospital, Dibrugarh, Assam.

2. Assistant Professor, Department of Pathology, Assam Medical College and Hospital, Dibrugarh, Assam.

3. Post Graduate Trainee, Department of Pathology, Assam Medical College and Hospital, Dibrugarh, Assam.

FINANCIAL OR OTHER COMPETING INTERESTS: None
4. Post Graduate Trainee, Department of Pathology, Assam Medical College and Hospital, Dibrugarh, Assam.

\section{NAME ADDRESS EMAIL ID OF THE CORRESPONDING AUTHOR:}

Dr. Reena Kouli, Associate Professor, Department of Pathology, Assam Medical College and Hospital, Dibrugarh-786002, Assam.

E-mail: koulir@gmail.com

Date of Submission: 23/09/2015. Date of Peer Review: 24/09/2015. Date of Acceptance: 05/10/2015. Date of Publishing: 15/10/2015. 